\title{
Carotenoides bixina e norbixina extraídos do urucum (Bixa orellana L.) como antioxidantes em produtos cárneos
}

\author{
Carotenoids bixin and norbixin from annatto (Bixa orellana L.) as antioxidants in meat products
}

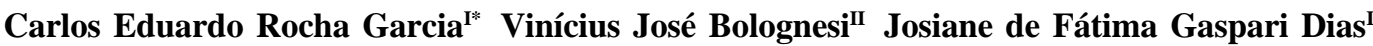 \\ Obdúlio Gomes Miguel ${ }^{\mathrm{I}}$ Camila Klocker Costa ${ }^{\mathrm{I}}$
}

\section{- REVISÃO BIBLIOGRÁFICA -}

\section{RESUMO}

A oxidação lipídica é uma das principais alterações que acometem os derivados cárneos em razão da composição química rica em lipídios e íons ferro, utilização de processos térmicos e de moagem, além do frequente uso do cloreto de sódio, um reconhecido catalisador desta reação. Os antioxidantes são substâncias utilizadas para inibir ou retardar a rancidez oxidativa, porém, seu uso desperta a atenção de consumidores e agências reguladoras, quanto à segurança que acompanha o consumo de aditivos sintéticos. Este trabalho teve por objetivo avaliar o uso dos carotenoides bixina $e$ norbixina como antioxidantes em produtos cárneos por meio da revisão de suas características químicas, métodos de obtenção, toxicidade e aplicações tecnológicas. Esses pigmentos são extraídos das sementes do urucum (Bixa orellana L.) por métodos que envolvem o uso de solventes orgânicos, extração supercrítica ou ainda a utilização da tecnologia de micro-ondas. No Brasil, o uso dessas substâncias é previsto na legislação como corante alimentício, porém, estes carotenoides apresentam extensas cadeias carbônicas insaturadas que permitem a adição de radicais livres $e$ lhes conferem a capacidade de atuar como antioxidantes. As diferenças estruturais entre bixina e norbixina resultam em particularidades quanto à polaridade, solubilidade, coloração $e$, por consequência, determinam singulares aplicações tecnológicas. Nas concentrações previstas pelas agências reguladoras, o consumo desses carotenoides é seguro e além das aplicações como corante, podem ser utilizados pela indústria como antioxidantes naturais, oportunizando uma alternativa capaz de substituir ou minimizar o uso de aditivos sintéticos em produtos cárneos.

Palavras-chave: aditivo, antioxidante natural, carne, corante, pigmento, rancidez, oxidação.

\section{ABSTRACT}

Lipid oxidation is one of the major modifications that affect meat products due to chemical composition, heat and grinding processes beyond the routine use of sodium chloride, a recognized catalyst of this reaction. Antioxidants are substances used to inhibit or retard oxidative rancidity. However the use of these compounds has been drawing the attention of consumers and regulatory agencies about the safety of synthetic additives consumption. This study aimed to evaluate the use of carotenoids bixin and norbixin as antioxidants in meat products by review of the chemical characteristics, methods of production, toxicity and technological applications. These pigments are extracted from annatto (Bixa orellana L.) using organic solvents, supercritical extraction or microwaves. In Brazil, the use of these substances is forecast by law as food colorant, however, this carotenoids show a large unsaturated carbon chains that allow the addition of free radicals and enable their use as antioxidant. The structural differences between bixin and norbixin result in distinct polarity, solubility and coloration, and consequently in different technological applications. At concentrations established by regulatory agencies, the use of these compounds is safe and, in addition to applications such as dyes, can be used by industries as natural antioxidants, which is an alternative capable of replace or minimize the use of synthetic additives in meat products.

Key words: additive, colorant, meat, natural antioxidant, pigment, rancidity, oxidation.

\section{INTRODUÇÃO}

A oxidação lipídica, também denominada rancidez oxidativa, é uma das principais alterações que

IDepartamento de Farmácia, Universidade Federal do Paraná (UFPR), 80210-170, Curitiba, PR, Brasil. E-mail: carlos.garcia@ufpr.br.

*Autor para correspondência.

${ }^{\mathrm{II} C u r s o}$ de Farmácia, UFPR, Curitiba, PR, Brasil. 
acometem as carnes e derivados, em razão da composição rica em lipídios e íons ferro, a utilização de processos como cocção e moagem, além do uso de cloreto de sódio, um reconhecido catalisador desta reação (ROCHA GARCIA et al., 2002). O desenvolvimento da rancidez oxidativa baseia-se no surgimento de radicais livres, espécies químicas que apresentam um ou mais elétrons desemparelhados, que podem ser gerados durante o metabolismo normal das células ou resultantes da ação de iniciadores, como a luz ou íons metálicos (GRAY et al., 1996).

O resultado das reações oxidativas nos alimentos é o surgimento de compostos oxigenados responsáveis pelas desagradáveis características organolépticas, reconhecidas popularmente como ranço, além do desenvolvimento de substâncias tóxicas, como a acroleína, malonaldeído (MDA) e os óxidos de colesterol (ROCHA GARCIA et al., 2002). O desenvolvimento dos processos oxidativos pode ser inibido por meio de alternativas como embalagens, utilizando vácuo ou atmosfera modificada, e o uso de substâncias antioxidantes (ROCHA GARCIA et al., 2003).

Os antioxidantes são substâncias que, em concentrações inferiores aos substratos oxidáveis, retardam ou previnem a oxidação destes, tornando-os indisponíveis para formação de espécies oxidantes (HALLIWELL \& GUTTERIDGE, 1999). A utilização desses aditivos é regulamentada por agências como a FAO (Food and Agriculture Organization), FDA (Food and Drug Administration) e, no Brasil, a ANVISA (Agência Nacional de Vigilância Sanitária), as quais estabelecem as substâncias e as concentrações permitidas para uso alimentício. A aprovação de um determinado antioxidante por essas agências, no entanto, não convence a todos os consumidores em relação à segurança de seu uso, sendo observado um crescente número de estudos relacionados à substituição dos aditivos sintéticos por similares obtidos diretamente da natureza (MARTINEZ-TOME et al., 2001).

A América Latina é o principal produtor mundial de urucum (Bixa orellana L), apresentando uma produção anual de aproximadamente $17 \mathrm{mil}$ toneladas, das quais 12 mil são originárias do Brasil (IBGE, 2009). O pericarpo maduro de suas sementes apresenta pigmentos de coloração amareloavermelhada atribuída à presença dos carotenoides bixina e norbixina. Em razão da intensidade das cores e da estabilidade frente às condições de processamento, os pigmentos do urucum são empregados como condimentos e corantes alimentícios (GIULIANO et al., 2003).
A legislação nacional regulamenta o uso do urucum e seus derivados como corante alimentício em produtos cárneos industrializados (BRASIL, 1998). No entanto, avaliações experimentais têm demonstrado a capacidade de seus carotenoides atuarem também como antioxidantes, indicando uma alternativa para substituição dos aditivos sintéticos e a necessidade de revisão da legislação que regulamenta suas aplicações em derivados cárneos. Nesse contexto, este trabalho teve por objetivo avaliar o uso dos carotenoides bixina e norbixina como antioxidantes em produtos cárneos por meio da revisão de suas características químicas, métodos de obtenção, toxicidade e aplicações tecnológicas.

\section{DESENVOLVIMENTO}

Propriedades químicas

O principal pigmento do urucum é a bixina, correspondendo a mais de $80 \%$ dos carotenoides encontrados nessas sementes (SATYANARAYANA et al., 2003). Esse composto corresponde, em média, a $2,5 \%$ do peso das sementes desidratadas e trata-se de um apocarotenoide, composto originado pela clivagem de carotenos, sendo essa ruptura mediada por enzimas que atuam em pontos específicos originando dois novos carotenoides (OLIVEIRA, 2005). A retirada do grupo metil éster da bixina origina a norbixina, um ácido dicarboxílico cuja estrutura está representada na figura 1.

As diferenças estruturais conferem à bixina características lipossolúveis, devido à presença do éster metílico na molécula, enquanto a norbixina apresenta maior hidrossolubilidade em razão da presença do grupamento carboxila (Figura 1), sítio de interações com moléculas de água (LIMA et al., 2001). RIOS \& MERCADANTE (2004) citam a bixina como carotenoide de maior concentração nas soluções coloríficas lipossolúveis do urucum, enquanto a norbixina é predominante nas preparações hidrossolúveis.

No entanto, não pode ser negligenciado que estes compostos sofrem isomerização devido à instabilidade das insaturações presentes na molécula frente às condições de processamento. Os isômeros cis, tanto da bixina quanto da norbixina, estão presentes naturalmente na planta, sendo convertidos na forma trans, mais estável, quando submetidos a altas temperaturas. As diferenças estruturais entre os isômeros cis e trans resultam em particularidades nas características físicas. A bixina, embora solúvel em soluções de reduzida polaridade, quando presente na forma do isômero cis não apresenta extensa solubilidade em óleos vegetais em razão da polaridade provida pelos grupos situados no mesmo lado da 
<smiles>CCOCCOCCCCC(=O)C=CC(C)=CC=CC(C)=CC=CC=C(C)C=CC=C(C)C=CC(=O)OC</smiles>

estrutura. Por outro lado, a trans-bixina é solúvel em óleos e proporciona coloração vermelha, diferindo do isômero cis, de coloração alaranjada (SATYANARAYANA et al., 2003).

Os carotenoides originados do urucum podem sofrer degradação quando expostos à luz ou submetidos a elevadas temperaturas (SATYANARAYANA et al., 2003). Diante do exposto, a aplicação desses corantes em alimentos deve considerar as características das matérias-primas, efeito corante ou antioxidante desejado, além das condições de processamento e armazenamento para que seja alcançada a aplicação tecnológica desejada.

Métodos de obtenção

Atualmente, diversos métodos são utilizados para extração de compostos antioxidantes em vegetais, desde técnicas tradicionais, utilizando solventes orgânicos (OLIVEIRA, 2005), como também processos mais avançados, como a extração supercrítica (LEAL et al., 2003) e a utilização de microondas (VASU et al., 2010).

A extração dos carotenoides das sementes de urucum tem sido realizada utilizando óleos vegetais, solventes orgânicos ou soluções alcalinas de $\mathrm{NaOH}$, $\mathrm{KOH}, \mathrm{NaHCO}_{3} \mathrm{eNH}_{4} \mathrm{OH}$ (OLIVEIRA, 2005). A FAO descreve seis diferentes extratos de urucum caracterizados pelas concentrações finais de cada carotenoide e pelos métodos utilizados para obtenção.
Extrações realizadas por meio de solventes orgânicos alcançam concentrações próximas a $92 \%$ de carotenoides e a proporção de cada pigmento ao final é influenciada pela acidez do meio extrator (JOINT-FAO, 2002).

A bixina pode ser extraída pelo método tradicional de Soxhlet, proporcionando um rendimento de aproximadamente 1,3\% de bixina (BARBOSA FILHO, 1998). No entanto, inovações nesse método, propostas por COSTA (2007), objetivando o esgotamento total dos pigmentos, proporcionaram concentrações de $3,6 \%$ deste carotenoide. Neste método, as sementes foram secas, fragmentadas e submetidas à extração por 6 horas utilizando clorofórmio como solvente. O sistema de percolação convencional foi substituído por uma placa de teflon perfurada e recoberta com algodão. Obteve-se deste processo um concentrado de intensa coloração vermelho-púrpura, caracterizado como bixina por meio de ressonância magnética nuclear de hidrogênio e carbono ( $\mathrm{RMN}$ de ${ }^{1} \mathrm{H} \mathrm{e}{ }^{13} \mathrm{C}$ ).

A extração supercrítica é uma técnica moderna e eficiente pautada no uso da pressão para liquefação do solvente extrator e sua posterior evaporação, proporcionando a obtenção de um produto final isento de solventes. Este método pode ainda ser melhorado pelo uso de co-solventes, como metanol e etanol, objetivando melhorar o rendimento da extração (POKORNY \& KORCZAK, 2001). O uso de $\mathrm{CO}_{2}$ como fluído supercrítico oferece vantagens por se tratar de um gás inerte, atóxico, não inflamável, de custo reduzido

Ciência Rural, v.42, n.8, ago, 2012. 
e gasoso nas condições normais, facilitando a separação dos solutos. O processo é desenvolvido em temperaturas relativamente baixas, favorecendo a obtenção de compostos termolábeis e preservando melhor os extratos. Por outro lado, esta tecnologia apresenta elevado custo operacional, inviabilizando, por vezes, a aplicação industrial (SILVA et al., 2008).

SILVA et al. (2008) utilizaram a extração supercrítica com $\mathrm{CO}_{2}$ para obter bixina a partir do urucum e observaram que o óleo presente nestas sementes atua como um co-solvente, aumentando a solubilidade da bixina em aproximadamente dez vezes. Essa elevada solubilidade indica que a aplicação desta tecnologia é adequada industrialmente, pois permite a obtenção de produtos livres de solventes orgânicos, particularidade especialmente interessante na obtenção de pigmentos para uso alimentício.

A extração por micro-ondas é um método de obtenção caracterizado pela simplicidade, efetividade e por otimizar o rendimento do processo, enquanto requer menos tempo e menor uso de solventes (MANDAL et al., 2007). A presença de água é um requisito fundamental na extração por micro-ondas, pois se trata do meio absorvente de radiação e gerador do calor responsável por promover a ruptura das células vegetais e liberar seus fitoconstituntes. VASU et al. (2010) compararam a extração de bixina a partir de sementes do urucum utilizando o método de extração por micro-ondas e o método tradicional, pautado no aquecimento das sementes em solução de acetato de etila. A extração por micro-ondas foi realizada por 18 minutos, novamente em meio contendo água e acetato de etila, e proporcionou o dobro do rendimento, demonstrando a eficiência e rapidez dessa técnica. As análises antioxidantes realizadas com a bixina obtida pelas duas técnicas foram semelhantes, indicando que não há alteração nas propriedades químicas dos carotenoides obtidos pela extração assistida por microondas.

\section{Toxicidade}

Estudos têm sido desenvolvidos objetivando determinar as concentrações de urucum em produtos alimentícios. Essas avaliações demonstram amplas variações resultantes da composição do extrato de urucum utilizado e também em razão das concentrações aplicadas serem dependentes da matriz alimentícia, estado físico, opacidade do produto e coloração desejada (TENNANT \& CALLAGHAN, 2005). No entanto, em 2002, o Comitê de Especialistas em Aditivos Alimentares (JECFA) da FAO/WHO determinou um limite para ingestão de extrato de urucum, composto basicamente por bixina, de, no máximo, $0,065 \mathrm{mg} \mathrm{kg}^{-1}$ de peso corpóreo/dia (JOINT-FAO, 2002). PAUMGARTTEN et al. (2002) investigaram uma eventual toxicidade associada ao consumo do urucum desidratado, contendo $28 \%$ de bixina, em ratas prenhas. Nesse estudo, foram administradas por via oral até $500 \mathrm{mg} \cdot \mathrm{kg}^{-1}$ de massa corporal ao dia, entre o $6^{\circ}$ e $15^{\circ}$ dia de gravidez. Nenhum efeito adverso foi observado nas ratas ou fetos, sugerindo que o urucum não apresenta toxicidade ou embriotoxicidade nestas condições. Eventuais efeitos tóxicos do extrato do urucum, contendo $5 \%$ de bixina, foram avaliados em ratos machos, submetendo-os a uma alimentação formulada com 20, 200 e 1000ppm por 15 semanas. No entanto, as análises realizadas em células sanguíneas e do cólon destes animais não demonstraram indícios de danos celulares (AGNER et al., 2005).

YOSHINO et al. (2003) avaliaram a toxicidade crônica do urucum em ratos alimentados por 13 semanas com dieta contendo $0,1,0,3$ e $0,9 \%$ de extrato (contendo $91,6 \%$ de norbixina) em relação ao peso corpóreo dos animais. Na concentração de $0,1 \%$, equivalente a $69 \mathrm{mg}$ $\mathrm{kg}^{-1}$ peso corpóreo/dia para machos ou $76 \mathrm{mg} \mathrm{kg}^{-1}$ peso corpóreo por dia para fêmeas, não foram observadas alterações no consumo de água, ganho de peso e nos padrões hematológicos ou oftalmológicos. $\mathrm{O}$ aumento de peso do fígado, em ambos os sexos, foi verificado após duas semanas de tratamento somente nos grupos que consumiram 0,3 e $0,9 \%$ do extrato, constatando-se hipertrofia hepática nos animais submetidos às maiores concentrações.

Em contraposição aos trabalhos indicando a ausência de toxicidade dos componentes do urucum, SILVA et al. (2000) aplicaram um modelo teórico baseado em cálculos que analisam trocas energéticas e transferência de elétrons para compostos com potencial carcinogênico. Os autores demonstraram que não pode ser descartada uma possível ação cancerígena da bixina, embora sejam necessários maiores estudos sobre sua rota metabólica para confirmação deste efeito.

A FAO, periodicamente, revisa os estudos publicados, visando a manter constante atualização sobre a inocuidade das substâncias utilizadas em alimentos. Assim como descrito em relatórios anteriores, no ano de 2006, a organização reafirmou que os extratos de urucum não apresentam potencial tóxico e seu uso é seguro nas concentrações determinadas para alimentos (JOINT-FAO, 2006).

No entanto, à medida que novos estudos são realizados, torna-se necessária contínua avaliação da toxicidade desses pigmentos. Estudos posteriores à compilação de resultados promovida pela FAO demonstraram que não pode ser negligenciada uma 
eventual toxicidade dos pigmentos em situações específicas. OUYIANG et al. (2008) concluíram que, embora a bixina individualmente não promova danos ao DNA, quando associada ao íon cúprico, um metal de reconhecida atividade oxidante, os componentes do urucum desenvolvem um efeito oxidativo sinérgico e podem apresentar efeitos deletérios sobre o material genético.

Ensaios avaliando a resposta alérgica aos componentes do urucum foram desenvolvidos por AUTTACHOAT et al. (2011). Nesse estudo, o urucum desidratado e os extratos concentrados dos carotenoides bixina $(84,10 \%)$ e norbixina $(98,18 \%)$ diluídos em veículos oleosos foram individualmente aplicados $(25 \mu \mathrm{L})$ em camundongos fêmeas. O urucum desidratado promoveu discreto efeito positivo em provas utilizadas para identificar potencial alergênico, seja no teste de inchaço de orelha ou na avaliação de proliferação celular no nódulo linfático. Os mesmos testes foram realizados utilizando os concentrados de carotenoides, porém, mesmo aplicada em soluções de maiores concentrações (10\%), a norbixina não provocou os mesmos efeitos. Por outro lado, a bixina induziu a sensibilização em concentrações significativamente inferiores $(0,5 \%)$.

Os experimentos que demonstraram uma eventual toxicidade dos derivados do urucum utilizaram concentrações amplamente superiores aos limites de ingestão determinados pela FAO, demonstrando que, à luz dos conhecimentos atuais, o uso dos derivados do urucum não compromete a segurança dos alimentos quando em acordo com a legislação vigente. No Brasil, o uso do urucum nas carnes é regulamentado pela portaria no $1004 \mathrm{da}$ ANVISA, que limita concentrações máximas de até

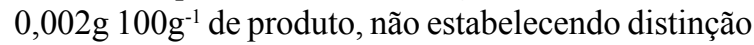
se utilizado como extrato ou carotenoide isolado na forma de bixina ou norbixina (BRASIL, 1998). Essa condição deveria ser revista pela ANVISA, pois, como observado na literatura, os extratos de urucum apresentam diferentes composições, além de serem observadas particularidades quanto a uma eventual toxicidade segundo os diferentes carotenoides do urucum.

Atividade antioxidante dos carotenoides do urucum A extensa cadeia de duplas ligações presente na estrutura dos carotenoides proporciona variações de distribuição eletrônica que permitem a adição de radicais livres aos carbonos adjacentes às insaturações, característica que proporciona maior reatividade dessas moléculas frente a agentes oxidantes, sobretudo derivados oxigenados, proporcionando relativa estabilidade. A interação com o carotenoide reduz a concentração de oxigênio no meio, diminuindo a quantidade de radical peróxido formada e, por consequência, inibindo a auto-oxidação (BURTON, 1989; KIOKIAS \& GORDON, 2003).

Diversos estudos têm observado o efeito antioxidante dos derivados do urucum, a bixina e outras substâncias naturais (luteína, licopeno, â-caroteno, e ã-tocoferol) foram avaliadas por HAILA et al. (1996) quanto a suas capacidades antioxidantes. Verificou-se que a bixina apresentou destacado efeito antioxidante, reduzindo a formacão de hidroperóxidos em triacilglicerídeos oxidados pela luz. KIOKIAS \& OREOPOULOU (2006) também avaliaram individualmente o extrato de urucum, â -caroteno, luteína e licopeno quanto a suas capacidades de inibir a formação de hidroperóxidos em uma emulsão aquosa, cuja oxidação foi estimulada pelo uso do 2,2'-azobisamidinopropano (AAPH). Nesse experimento, o extrato de urucum superou as demais substâncias naturais, apresentando a maior atividade antioxidante.

MARTÍNEZ-TOMÉ et al. (2001) avaliaram a atividade antioxidante dos condimentos urucum, alecrim (Rosmarinus officinalis), páprica (Capsicum annum), cominho (Cuminum cyminum), orégano (Origanum vulgare) e açafrão (Crocus sativus), comparando suas atividades antioxidantes em meio aquoso a similares sintéticos, como o butil hidroxianisol (BHA), butil hidroxitolueno (BHT) e galato de propila. De forma geral, pode ser verificado que, em diversos testes, a ação antioxidante dos condimentos naturais sobrepõem-se às substâncias sintéticas. Isso sugere uma vantagem na substituição de compostos sintéticos em alimentos por condimentos naturais, uma vez que, além de ofertarem gosto e cor, também proporcionam estabilidade oxidativa.

Uso dos carotenoides do urucum como antioxidantes em produtos cárneos

A utilização de antioxidantes naturais em produtos cárneos vem sendo avaliada há anos com o objetivo de substituir ou, ao menos, minimizar o uso de aditivos sintéticos, satisfazendo a demanda de consumidores ávidos por produtos de características naturais (CIRIANO et al., 2010; JAYATHILAKAN et al., 2007; GARRIDO et al., 2011; MAQSOOD et al., 201). $\mathrm{O}$ urucum destaca-se entre os aditivos naturais utilizados nos produtos cárneos, porém, embora seu efeito antioxidante tenha sido reportado na literatura, a legislação nacional limita suas aplicações tecnológicas ao emprego como corante, vetando ainda seu uso em carnes frescais ou congeladas (BRASIL, 1998). 
FREITAS CASTRO (2008) avaliou o efeito antioxidante do urucum durante o processamento térmico e armazenamento de hambúrgueres elaborados com peito de frango (Pectoralis major). A quantificação de MDA demonstrou que, embora a concentração de bixina seja reduzida durante o processamento térmico, seu uso minimizou a rancidez oxidativa em todas as determinações realizadas durante os 120 dias de armazenamento $\mathrm{a}-18^{\circ} \mathrm{C}$. Nas amostras cruas, não foram verificadas diferenças oxidativas resultantes do uso do colorífico, porém, foi possível identificar um efeito protetor do urucum sobre os níveis de vitamina $\mathrm{E}$, substância de reconhecido efeito antioxidante, durante o período de armazenamento do produto, quando utilizados associados.

MERCADANTE et al. (2010) avaliaram o uso individual de substâncias naturais (norbixina, â caroteno, licopeno e zeaxantina) utilizadas como substituintes do antioxidante sintético eritorbato de sódio em salsichas formuladas com mistura de carnes bovina, suína e de frango. Embora todos os pigmentos tenham sido capazes de manter a estabilidade oxidativa do produto, a norbixina e a zeaxantina apresentaram os maiores efeitos antioxidantes, promovendo uma redução de aproximadamente $20 \%$ nos níveis de MDA. Um estudo realizado por ZARRINGHALAMI et al. (2009) avaliou a estabilidade da cor em salsichas formuladas com duas diferentes proporções de carne (55 e 70\%) e variáveis concentrações de nitrito e urucum desidratado ( $1 \%$ de norbixina). $\mathrm{O}$ produto foi mantido sob refrigeração a $4^{\circ} \mathrm{C}$, sendo realizadas tomadas de amostras no $2^{\circ}, 10^{\circ}$, $20^{\circ}$ e $30^{\circ}$ dias. Os resultados demonstraram a estabilidade da coloração vermelha atribuída pelo urucum por 30 dias de armazenamento, indicando-o como possível substituto do nitrito, quando o objetivo é aumentar a intensidade da coloração vermelha do produto ou ainda para minimizar os níveis de nitrito e, por consequência, a formação de nitrosaminas. Embora o nitrito seja considerado um conservante pela legislação vigente (BRASIL, 1998), este sal também é utilizado como antioxidante nos produtos cárneos (CASSENS, 1995), função que pode ser atribuída pelos derivados do urucum.

\section{CONCLUSÃO}

A bixina e norbixina, além das aplicações tecnológicas como corantes, também podem ser utilizadas pela indústria como antioxidantes naturais, proporcionando uma alternativa capaz de substituir ou minimizar o uso de aditivos sintéticos em derivados cárneos. No entanto, a legislação que regulamenta o uso do urucum nestes produtos deve ser revista, passando a prever a função de antioxidante e determinando concentrações limites, específicas para os extratos e carotenoides isolados, permitindo o controle dos processos oxidativos sem comprometer a segurança de seu consumo.

\section{AGRADECIMENTOS}

Os autores agradecem ao Conselho Nacional de Desenvolvimento Científico e Tecnológico $(\mathrm{CNPq})$, pelo apoio financeiro ao projeto.

\section{REFERÊNCIAS}

AGNER, A.R. et al. Absence of carcinogenic and anticarcinogenic effects of annatto in the rat liver medium-term assay. Food and Chemical Toxicology, v.42, n.10, p.1687-1693, 2005. Disponível em: <http://www.sciencedirect.com/science/article/pii/ S1383571805000367>. Acesso em: 2 set. 2010. doi:10.1016/ j.mrgentox.2005.01.009.

ANVISA - Agência Nacional de Vigilância Sanitária. Atribuição de função de aditivos, aditivos e seus limites máximos de uso para a categoria 8 - carne e produtos cárneos. Portaria $\mathrm{n}^{\mathrm{o}} 1.004$, de 11 de dezembro de 1998.

AUTTACHOAT, W. et al. Contact sensitizing potential of annatto extract and its two primary color components, cisbixin and norbixin, in female BALB/c mice. Food and Chemical Toxicology, 2011. Disponível em: <http:// ww w.s ciencedirect.com/s cience/article/pi i S0278691511003322>. Acesso em: 17 ago. 2011. doi:10.1016/ j.fct.2011.07.009

BARBOSA FILHO, J.M. et al. Teor de bixina em quatro variedades de Bixa orellana L. cultivadas na Paraíba. Revista Brasileira de Farmacognosia, v.7/8, p 41-47, 1998.

BURTON, W.G. Antioxidant action of carotenoids. Journal of Nutrition, v.119, p.109-111, 1989. Disponível em: <http:/ /jn.nutrition.org/content/119/1/109.full.pdf>. Acesso em: 7 ago. 2010. doi: 0022-3166/89.

CASSENS, R.G. Use of sodium nitrite in cured meats today. Food Technology, v.52, n.10, p.54-59, 1995. Disponível em: $<$ http://www.sciencedirect.com/science/article/pii/ S030881469700007>. Acesso em: 11 set. 2010. doi: 10.1016/ S0308-8146(97)00007-1.

CIRIANO, M.G-I. et al. Selenium, iodine, ù-3 PUFA and natural antioxidante from Melissa officinalis L.: A combinationa of components from healthier dry fermented sausages formulation. Meat Science, v.85, p.274-279, 2010. Disponível em: $<\mathrm{http}$ :/ /www.sciencedirect.com/science/article/pii/ S030917401000015X>. Acesso: 20 jul. 2011. doi:10.1016/ j.meatsci.2010.01.012.

COSTA, C.K. Estudo fitoquímico de bixa orellana, bixacea e aplicação de óleo em formulação cosmética. 2007. $98 \mathrm{f}$. Dissertação (Mestrado em Ciências Farmacêuticas) Universidade Federal do Paraná, Curitiba, PR. 
FREITAS CASTRO, W. Avaliação do efeito protetor do colorífico como antioxidante natural na oxidação lipídica em carne de frango. 2008. 84f. Dissertação (Mestrado em ciência de alimentos - Universidade Estadual de Campinas, Campinas, SP.

GARRIDO, M.D. et al. Effect of two red grape pomace extracts obtained under different extraction systems on meat quality of pork burguers. Lebensmittel-Wissenschaft und Technologie, 2011. Disponível em: <http://www.sciencedirect.com/science/ article/pii/S0023643811002040>. Acesso em: 20 jul. 2011. doi: 10.1016/j.lwt.2011.07.003.

GIULIANO, G. et al. To dye or not to dye: biochemistry of annatto unveiled. Trends in Biotechnology, v.21, n.12, p.513516, 2003. Disponível em: <http://www.sciencedirect.com/ science/article/pii/S0167779903002762>. Acesso em: 2 ago. 2011. doi:10.1016/j.tibtech.2003.10.001

GRAY, J.I. et al. Oxidative quality and shelf life of meats. Meat Science, v.43, n.8, p.111-123, 1996. Disponível em: $<$ http://www.sciencedirect.com/science/article/pii/ 0309174096000599>. Acesso em: 27 ago. 2010. doi: 10.1016/ 0309-1740(96)00059-9.

HAILA, H. et al. Effects of lutein, lycopene, annatto and ãtocopherol on autoxidation of triglycerides. Journal of Agricultural and Food Chemistry, v.44, n.6, p.2096-2100, 1996. Disponível em: <http://pubs.acs.org/doi/abs/10.1021/ jf9504935>. Acesso em: 19 ago. 2010. doi: 10.1021/jf9504935.

HALLIWELL, B.; GUTTERIDGE, J.M.C. Free radicals in biology and medicine. 5.ed. Oxford: Claredon, 1999. 899p.

IBGE - Instituto Brasileiro de Geografia e Estatística. Produção da extração vegetal e silvicultura, v.24, 2009. 45 p. Disponível em: <http://www.ibge.gov.br/home/estatistica/ economia/pevs/2009/>. Acesso em: 21 ago. 2011. ISSN: 01038435 .

JAYATHILAKAN, K. et al. Antioxidant potential of synthetic and natural antioxidants and its effect on warmed-over-flavour in different species of meat. Food Chemistry, v.105, p.908916, 2007. Disponível em: <http://www.sciencedirect.com/ science/article/pii/S0308814607003913>. Acesso em: 3 nov. 2010. doi:10.1016/j.foodchem.2007.04.068.

JOINT FAO/WHO EXPERT COMMITTEE ON FOOD ADDITIVES. List of substances scheduled for evaluation and request for data. Roma: 2002. 16p.

JOINT FAO/WHO EXPERT COMMITTEE ON FOOD ADDITIVES. Sixty-seventh report of the Joint FAO/WHO Expert Committee on Food Additives. Roma, 2006. ISSN 0512-3054. 104p.

KIOKIAS, S.; GORDON, M.H. Antioxidant properties of annatto carotenoids. Food Chemistry, v.83, p.523-529, 2003. Disponível em: <http://www.sciencedirect.com/science/article/ pii/S0308814603001481>. Acesso em: 16 abr. 2010. doi:10.1016/S0308-8146(03)00148-1.

KIOKIAS, S.; OREOPOULOU, V. Antioxidant properties of natural carotenoid extracts against the AAPH-iniciated oxidation of food emulsions. Innovative Food Science \& Emerging Technologies, v.7, p.132-139, 2006. Disponível em: <http://www.sciencedirect.com/science/article/pii/ S1466856406000191>. Acesso em: 16 mar. 2010. doi:10.1016/ j.ifset.2005.12.004.

LEAL, P.F. et al. Functional properties of spices extracts obtained via supercritical fluid extraction. Journal of Agricultural and Food Chemistry, v.51, n.9, p.2520-2525, 2003.

LIMA, L.R.P. et al. Bixina, norbixina e quercetina e seus efeitos no metabolismo lipídico de coelhos. Brazilian Journal of Veterinary Research and Animal Science, v.38, n.4, p.196200, 2001. Disponível em: <http://www.scielo.br/pdf/bjvras/ v38n4/9706.pdf>. Acesso em: 18 out. 2010.

MANDAL, V. et al. Microwave assisted extraction - An innovative and promising extraction tool for medicinal plant research. Pharmacognosy Reviews, v.1, p.7-18, 2007. Disponível em: $<$ http://www.sineo.cn/pic/article/42.pdf $>$. Acesso em: 15 ago. 2011.

MAQSOOD, S. et al. Effect of tannic acid and kaim wood extract on lipid oxidation and textural properties of fish emulsions sausages during refrigerated storage. Food Chemistry, 2011. Disponível em: < http://www.sciencedirect.com/science/article/pii/ S0308814611010260\#FCANote>. Acesso em: 10 ago. 2011. doi: 10.1016/j.foodchem.2011.07.065.

MARTINEZ-TOME, M. et al. Antioxidant properties of mediterranean spices compared with common food additives. Journal of Food Protection, v.64, n.9, p.1412-1419, 2001. Disponível em: <http://www.ingentaconnect.com/content/iafp/ jfp/2001/00000064/00000009/art00021>. Acesso em: 7 jul. 2011. ISSN 0362-028X.

MERCADANTE, A.Z. et al. Effect of natural pigments on the oxidative stability of sausages stored under refrigeration. Meat Science, v.84, p.718-726. 2010. Disponível em: <http:// w w w.sciencedirect.com/science/article/pi i/ S0309174009003660>. Acesso em: 16 mar. 2010. doi:10.1016/ j.meatsci.2009.10.031

OLIVEIRA, J.S. Purificação de compostos de urucum por processo absortivo. 2005. 185f. Tese (Doutorado em Engenharia Química) - Universidade Federal de Santa Catarina, Florianópolis, SC.

OUYANG, D. et al. A synergistic effect of $\mathrm{Cu}^{2+}$ and norbixin on DNA damage. Food and Chemical Toxicology, v.46, n.8, p.2802-2807, 2008. Disponível em: <http:// www.sciencedirect.com/science/article/pi i/ S0278691508002500>. Acesso em: 17 ago. 2011. doi: $10.1016 /$ j.fct.2008.05.021.

PAUMGARTTEN, F.J.R. et al. Evaluation of the developmental toxicity of annatto in the rat. Food and Chemical Toxicology, v.40, n.11, p.1595-1601, 2002. Disponível em: <http:// ww w.sciencedirect.com/science/article/pi i/ S0278691502001333>. Acesso em: 5 jun. 2011. doi:10.1016/ S0278-6915(02)00133-3.

POKORNY, J.; KORCZAK, J. Preparation of natural antioxidants. In: POKORNY, J. et al. Antioxidants in food: practical applications. New York: CRC, 2001. p.311-330. 
RIOS, A.O.; MERCADANTE, A.Z. Otimização das condições para obtenção de padrão de bixina e das etapas de extração e saponificação para quantificação de bixina em "snacks" extrusados por CLAE. Alimentos e Nutrição, v.15, n.3, p.203-213, 2004 Disponível em: <http://serv-bib.fcfar.unesp.br/seer/index.php/ alimentos/article/viewArticle/78>. Acesso em: 2 ago. 2010. ISSN 01034283 .

ROCHA GARCIA, C.E. et al. Antioxidantes utilizados na indústria cárnea: quais são os aditivos inibidores da rancidez nos produtos cárneos. Revista Nacional da Carne, v.26, n.299, p.36-51, 2002. ISSN 1413-4837.

ROCHA GARCIA, C.E. et al. Preservation of spent leghorn hen meat by a drying and salting process. Journal of Applied Poultry Research, v.12, p.335-340, 2003. Disponível em: $<$ http://japr.fass.org/content/12/3/335.full.pdf + html $>$. Acesso em: 27 ago. 2010. ISSN 1537-0437.

ROCHA GARCIA, C.E. et al. Bixina e norbixina: os pigmentos do urucum (Bixa orellana L.) utilizados na indústria cárnea. Revista Nacional da Carne, v.401, p.14-22, 2010. ISSN 1413-4837.

SATYANARAYANA, A. et al. Chemistry, processing and toxicology of annatto (Bixa orellana L.). Journal of Food Science Technology, v.40, n.2, p.131-141, 2003. Disponível em: <http://onlinelibrary.wiley.com/doi/10.1111/j.17454506.2006.00014.x/abstract>. Acesso em: 31 ago. 2010. doi: $10.1111 / \mathrm{j} .1745-4506.2006 .00014 . \mathrm{x}$

SILVA, M.P.F. et al. Isolamento e análise da possível ação carcinogênica da bixina comparada com a de outros corantes. In: REUNIÃO ANUAL DA SOCIEDADE BRASILEIRA DE
QUÍMICA, 23., 2000, Poços de Caldas. Disponível em: http:/ /www.sbq.org.br/ranteriores/23/resumos/1297/. Acesso em: 22 jan. 2006.

SILVA, G.F. et al. Extraction of bixin from annatto seeds using supercritical carbon dioxide. Brazilian Journal of Chemical Engineering, v.25, n.2, p.419-426, 2008. Disponível em: $<$ http://www.scielo.br/pdf/bjce/v25n2/a19v25n2.pdf $>$. Acesso em: 27 set. 2010. ISSN 0104-6632.

TENNANT, D.R.; CALLAGHAN, M.O. Survey of usage and estimated intakes of annatto extracts. Food Research International, v.38, p.911-917, 2005. Disponível em: <http:/ / ww w.sciencedirect.com/science/article/pi i/ S0963996905000955>. Acesso em: 17 mar. 2010. doi:10.1016/ j.foodres.2005.01.013.

VASU, S. et al. Microwave facilitated extraction of bixin from Bixa orellana and it's in-vitro antioxidant activity. Natural Product Research, v.24, n.16, p.1560-1567, 2010. Disponível em: <http:/ /www.tandfonline.com/doi/pdf/10.1080/14786419.2010.495071>. Acesso em: 19 dez. 2010. doi:10.1080/14786419.2010.495071.

YOSHINO, H. et al. Ninety-toxicity study of annatto extract, a natural food color, in rats. In: Proceedings of the $30^{\text {th }}$ annual meeting. Journal of Toxicological Sciences, v.28, n.4, p.294, 2003.

ZARRINGHALAMI, S. et al. Partial replacement of nitrite by annatto as a colour additive in sausage. Meat Science, v.81, p.281-284, 2009. Disponível em: <http://www.sciencedirect.com/ science/article/pii/S030917400800257X >. Acesso em: 16 mar. 2010. doi:10.1016/j.meatsci.2008.08.003. 